\title{
Biochemical Studies on Carbohydrates.
}

CVII. Amino Sugar in the Glycidamin Making up Chondromucoid.

By

\author{
Noboru Hiyama. \\ (懀 山 登)
}

(From the Medico-Chemical Institute, Tohoku Imperial University, Sendai. Director: Prof. H. Masamune.)

(Received for publication, April 2, 1947)

- Sasakil) reported that tendomucoid $\beta$ contains both glucosamine (in the glycidamin-moiety) and. chondrosamine (in the chondroitinsulfuric acid-moiety) and Osaki ${ }^{2}$ expressed a similar opinion on sclera mucoids. Viewed from these recent findings, Hisamura's announcement ${ }^{3}$ that the glycidamins in chondro- and osseo-mucoid contain chondrosamine as their hexosamine constituent looks to require reinvestigation, because cartilage and bone are mesenchymal derivatives similar to tendon and sclera. So I recrystallized Hisamura's preparations left over of hexosamine benzoate to see if their melting point rises thereby to approach that of glucosamine benzoate. The results came out as expected. Regretfully, however, the substance was too little for a detailed study which compelled me to start with separation of the glycidamins. The present account deals with the work on the hexosamine in chondromucoid-glycidamin. This glycidamin was prepared by removing chondroitinsulfuric acid from the mucoid with glycol and the hexosamine was isolated by fractioning its hydrolysate with butanol as from the jelly-forming proteins of toad and frog eggs.)

The obtained hydrochloride showed properties, chemical and physical, of glucosamine hydrochloride and gave an $\alpha$-hydroxynaphthylidene derivative identical with the corresponding derivative of this hexosamine.

\section{EXPERIMENTAL.}

Chondromucoid and its Glycidamin.

Chondromucoid was prepared from whale nasal cartilage. The extraction and following precipitation were performed according to the first method of C. Th. Mörner ${ }^{5)}$ and the precipitates washed with a dilute HCl 
of $\mathrm{pH} 1.8$ exhaustivily and, then with alcohol and ether in sequence and dried. ${ }^{6)}$

To separate the glycidamin moiety, $1 \mathrm{gm}$. of the above mucoid was kneaded with a small portion of glycol and after increasing glycol to $20 \mathrm{cc}$., $1 \mathrm{n}$. $\mathrm{NaOH}$ added in drops to slightly alkaline, whereby the mixture took pasty appearance, the mucoid having been dissolved almost entirely. The glycidamin was precipitated by bringing the $\mathrm{pH}$ to 6.5 with several drops of $1 \mathrm{n} . \mathrm{HCl}$ and separated by prolonged centrifugation. The centrifugate was washed twice with $20 \mathrm{cc}$. glycol with repeated centrifugations and many times with alcohol. Alcohol was replaced with ether, which was evaporated off. Yield, $515 \mathrm{mgm}$. It gave positive biuret, Molisch, Osaki-Turumi (both the direct and indirect) and Hiyama ${ }^{7)}$ reactions. The naphthoresorcinol test for hexuronic acid (Neuberg-Saneyoshi) resulted in negative. Quantitative analysis gave: nitrogen $12.82 \%$, hexosamine $12.63 \%$, galactose $12.05 \%$ (the indole method: $12.2 \%$, the orcinol method: $11.5 \%$, the $\alpha$-naphthol method I: $12.4 \%$ ), hydrolysable sulfur $1.34 \%$, ash $0.43 \%$.

\section{Isolation of the Hexosamine from the Hydrolysate of the Glycidamin.}

The procedure described in the third report concerning the jelly of toad and frog eggs ${ }^{4}$ ) was followed with minor modifications as below.

$1.8 \mathrm{gm}$. of the glycidamin separated was hydrolyzed with $20 \mathrm{cc}$. of $20 \% \mathrm{HCl}$ containing $0.8 \mathrm{gm}$. of stannous chloride by boiling under reflux for 15 hours on a sand bath (The substance was dissolved in advance on a water bath). Without removing the dark sediments, which had appeared during the heating, the hydrolysate was diluted with double the volume of water and bubbled with $\mathrm{H}_{2} \mathrm{~S}$-gas. The excess $\mathrm{H}_{2} \mathrm{~S}$ was expelled by aeration and the precipitates and the above sediments were filtered off together and washed with hot water on the funnel and followingly in a beaker. The yellowish transparent filtrate combined with the washings was evaporated under reduced pressure $\left(40^{\circ} \mathrm{C}\right)$ to a syrup, evaporated again twice with $5 \mathrm{cc}$. of water and finally taken up in, $14 \mathrm{cc}$. of water for fractionation with butanol in a Dakin's apparatus. Extraction was continued for 6 hours and the inspissated fluid $(1.5 \mathrm{cc}$.) was diluted with', water, the appearing precipitates centrifuged off and the supernatant liquid condensed by vacuum distillation to about $0.5 \mathrm{cc}$. To this condensate $0.5 \mathrm{cc}$. of concentrated $\mathrm{HCl}$ and $5 \mathrm{cc}$. of absolute alcohol were added and some precipitates filtered off. And to the filtrate was added acetone cautiously until faint cloudiness occurred. Crystallization began after a while. Acetone was supplemented thereafter from time to time and when oily deposit began to appear, the crystals were separated, washed with absolute alcohol and ether and dried in a desiccator $\left(\mathrm{CaCl}_{2}\right)$. Yield, $71 \mathrm{mgm}$. 
The crude product was dissolved in $1 \mathrm{cc}$. of water mixed with a few drops of concentrated $\mathrm{HCl}$. On addition of $10 \mathrm{cc}$. of absolute alcohol beautiful crystals came out in plates (hexagonal, tetragonal and trigonal). After further addition of a little acetone and keeping the mixture in an ice chest overnight, the crystals were collected. Yield, $60 \mathrm{mgm}$.

The substance began browning at about $180^{\circ} \mathrm{G}$, but did not melt even at $250^{\circ} \mathrm{C}$. Red colouration developed by $p$-dimethylaminobenzaldehyde, when it had been heated preliminarily with an alkaline acetylacetone solution. The positive chloride test was given. It reduced hot Fehling solution.

$\mathrm{N}$ (micro Kjeldahl method).

2.85 mgm. substance, $1.349 \mathrm{cc} .0 .01 \mathrm{n}$. acid neutral. by $\mathrm{NH}_{3}$.

$\mathrm{C}_{6} \mathrm{H}_{13} \mathrm{O}_{5} \mathrm{~N} \cdot \mathrm{HCl}$. Calc. $6.50 \%$, found $6.63 \%$.

Optical rotation (in water).

5 minutes after dissolution:

$$
[\alpha]_{\mathrm{D}}^{18}=\frac{1.389 \times 100}{1.425 \times 1}=+97.5^{\circ},
$$

24 hours after dissolution:

$$
[\alpha]_{\mathrm{D}}^{18}=\frac{1.035 \times 100}{1.425 \times 1}=+72.6^{\circ} \text {. }
$$

The mutarotation proceeded as is seen in Table $\mathrm{I}$.

$$
\text { TABLE I. }
$$

Course of Mutarotation in Water of the Hexosamine hydrochloride from Chondromucoid-glycidamin.

\begin{tabular}{c|c|c}
\hline $\begin{array}{c}\text { Time after } \\
\text { dissolution } \\
\text { min. }\end{array}$ & $\begin{array}{c}\alpha \\
\text { deg. }\end{array}$ & {$[\alpha]_{D}^{18}=\frac{\alpha \times 100}{1.425 \times 1}$} \\
$\mathrm{deg}$.
\end{tabular}

The initial $[\alpha]_{\mathcal{D}}$ extrapolated is $+100^{\circ}$. This and the rotation at equilibrium agree perfectly with Irvine and Earl's values ${ }^{8)}$ of $\alpha$-glucosamine hydrochloride.

The 2-Hydroxynaphthylidene Derivative of the Hexosamine in Question.

$40 \mathrm{mgm}$. of the hexosamine hydrochloride above were condensed with 
2-hydroxynaphthaldehyde by the method of Jolles and Morgan". The excess of the aldehyde was removed by means of ether. The crude product ( $48 \mathrm{mgm}$.) melted at $187-190^{\circ} \mathrm{C}$ (decomp.) and the twice recrystallized from hot methanol $\left(38 \mathrm{mgm}\right.$.) at $202^{\circ} \mathrm{C}$ (decomp.). Most of the crystals took a needle form and the remaining the form of plate. Its mixture with the corresponding Schiff's base of glucosamine (below) with F. P. of $200^{\circ} \mathrm{C}$ (decomp.) melted without any depression.

$\mathrm{N}$ (micro Kjeldahl method with antecedent reduction by means of $\mathrm{HI}$ and red phosphorus).

6.50 mgm. substance, 1.881 cc. 0.01 n. acid neutral. by $\mathrm{NH}_{3}$. $\mathrm{C}_{17} \mathrm{H}_{19} \mathrm{O}_{6} \mathrm{~N}$. Calc. $4.20 \%$, found $4.13 \%$.

Optical rotation (in methanol). It had the initial rotation (12 minutes after dissolution) $[\alpha]_{\mathrm{D}}^{16}=\frac{0.695 \times 100}{0.343 \times 1}=+202.6^{\circ}$ and the equilibrium rotation $[\alpha]_{\mathrm{D}}^{18}=\frac{0.601 \times 100}{0.343 \times 1}=+175.2^{\circ}$ (measured 24 hours after dissolution), which are in accord with those of the corresponding derivative of glucosamine hydrochloride (s. below). The equilibrium was secured in 6 hours.

A note on 2-hydroxynaphthylidene-glucosamine.

According to Jolles and Morgan this Schiff's base of glucosamine crystallizes in tufts of thin needles. The authors only described to have used "glucosamine hydrochloride," and so it was most probably a usual preparation, namely the $\alpha$-isomer. Although I subjected $\alpha$-glucosamine hydrochloride (Ledderhose) to the condensation by strictly following their technique (The excess aldehyde was extracted off with chloroform and ether), the product after one recrystallization from hot methanol took half and half the forms of tetragonal thick plate and of thin needle. By the second recrystallization it changed to a great part into needles, but needles alone could not be obtained by further recrystallization and the melting point remained constant. $130 \mathrm{mgm}$. were yielded from $150 \mathrm{mgm}$. of $\alpha$-glucosamine hydrochloride, and as to the melting point $\left(200^{\circ} \mathrm{C}\right.$ (decomp.)), solubility and nitrogen content $(4.17 \%)^{10)}$ the substance coincided with Jolles and Morgan's. And hydrolysis according to the same authors gave a nearly theoretical amount of glucosamine hydrochloride ${ }^{11}$ (13.5 mgm. glucosamine hydrochloride were given from $25 \mathrm{mgm}$. of the base). I could not measure its rotation of light of wave length $5461 \AA$ as the authors, but the initial $[\alpha]_{\mathrm{D}}$ was $+203.7^{\circ}\left([\alpha]_{\mathrm{D}}^{22}=\frac{0.780 \times 100}{0.383 \times 1}=+203.7^{\circ}\right)$ after 6 minutes from dissolution, which changed to $+174.4^{\circ}\left([\mathrm{a}]_{\mathrm{D}}^{22}=\frac{0.668 \times 100}{0.383 \times 1}\right.$ $\left.=+174.4^{\circ}\right)$ in 24 hours. 
I have already proved that the corresponding Schiff's bases of $a$ - and of $\beta$-chondrosamine and their mixture all melt at one and the same temperature $^{12)}$. Therefrom it is analogized that my product above was a mixture of the bases of $\alpha$ - and $\beta$-glucosamine and largely composed of the former.

The costs of this work were defrayed by a grant from the Education Department through the Grant Committee for Scientific Researches.

\section{Bibliography and Notes.}

1) Sasaki, Tohoku J. Exp. Med., 1945, 48, 307.

2) Osaki, ibid., 1947, 49, 19.

3) Hisamura, J. Bioch., 1938, 28, 217 and 473.

4) Hiyama, Tohoku J. Exp. Med., 1949, 50, 379 and 385.

5) C. Th. Mörner, Skand. Arch. f. Physiol., 1889, 1, 210.

6) Readers are referred to Masamune and Yasuoka, Tohoku J. Exp. Med., 1947, 49, 181.

7) Hiyama, Tohoku J. Exp. Med., in press.

8) Irvine and Earl, J. Chem. Soc. London, 1922, 121, 2370.

9) Jolles and Morgan, Bioch. J., 1940, 34, 1183.

10) Determined by the micro Kjeldahl method combined with reduction by means of $\mathrm{HI}$ and red phosphorus.

11) The product had the crystalline form of plate and did not melt even at $280^{\circ} \mathrm{C}$ on heating. The initial rotation (in water) was $[\alpha]_{D}^{3}=+95.5^{\circ}$ which changed to $+73.3^{\circ}$ in 24 hours. It gave the strongly positive Elson and Morgan test for hexosamine.

12) Hiyama, Tohoku J. Exp. Med., 1949, 50, 379. 